\title{
Efficacy and safety of rituximab in autoimmune and microangiopathic hemolytic anemia: a systematic review and meta-analysis
}

\author{
Shih-Hsuan Chao ${ }^{1}$, Yuh-Lih Chang ${ }^{2}$, Jiin-Cherng Yen ${ }^{1}$, Hsien-Tzung Liao ${ }^{3}$, Tsai-Hung Wu ${ }^{4}$, Chia-Li Yu ${ }^{5}$, \\ Chang-Youh Tsai ${ }^{3^{*}}$ (1) and Yueh-Ching Chou ${ }^{2}$
}

\begin{abstract}
Background: The efficacy and safety of rituximab (RTX) on hemolytic anemia (HA) is unknown. Therefore we retrospectively analyze the efficacy and safety of RTX in autoimmune hemolytic anemia (AlHA) and microangiopathic hemolytic anemia (MAHA) from the previous literature.

Methods: Data in clinical trials and observational studies were collected from PubMed, Cochrane, Embase, and Google Scholar until Oct 15, 2018. The efficacy and safety of RTX in patients with AlHA or MAHA were assessed and overall response rates (ORRs), complete response rates (CRRs), adverse events (AEs) and relapse rates (RRs) were extracted if available. A meta-analysis was performed with a random-effects model, estimating mean proportions in all studies, and relative rates in comparative studies.

Results: After quality assessment, a total of 37 investigations encompassing 1057 patients eligible for meta-analysis were included. Pooled mean proportion of ORR was 0.84 (95\% confidence interval [CI] 0.80-0.88), and that of CRR was 0.61 (95\% Cl 0.49-0.73). Mean AE rate was 0.14 (95\% Cl 0.10-0.17), and mean RR was 0.21 ( $95 \% \mathrm{Cl} 0.15-0.26$ ). Relative ORR was 1.18 (95\% Cl 1.02-1.36), and relative CRR was 1.17 (95\% Cl 0.98-1.39) fold more than the respective non-RTX counter parts. Relative AE rate was 0.77 (95\% Cl 0.36-1.63), and relative RR was 0.93 ( $95 \% \mathrm{Cl} 0.56-1.55)$ fold less than the respective non-RTX counter parts.
\end{abstract}

Conclusion: RTX is more effective than the treatments without RTX for AlHA and MAHA and is well-tolerated.

\section{Introduction}

Hemolytic anemia (HA) is an anemia due to premature destruction of erythrocytes (or red blood cells, RBCs) in the circulation before their normal demise [1]. Its diagnosis is based on decreased hemoglobin and/or haptoglobin, increased reticulocytes, indirect bilirubin, and lactate dehydrogenase, as well as typical findings

*Correspondence: cytsai@vghtpe.gov.tw

${ }^{3}$ Division of Allergy Immunology \& Rheumatology, Taipei Veterans General Hospital, 201 Shih-Pai Rd Sec 2, Taipei 112, Taiwan

Full list of author information is available at the end of the article demonstrated in peripheral blood smear $[1,2]$. There are several causes of HA, which may result in erythrocyte destruction occurring at different locations, such as in larger vessels in the case of autoimmune hemolytic anemia (AIHA) or in smaller vessels in the case of microangiopathic hemolytic anemia (MAHA) [2].

AIHA is caused by autoantibodies against selfantigens in erythrocytes, leading to a premature RBC destruction, which could be diagnosed by a positive direct antiglobulin test (DAT) [3]. AIHA can be subdivided into warm, mixed, or cold-reactive subtypes, according to the optimal autoantibody- $\mathrm{RBC}$ reactivity

(c) The Author(s) 2020. This article is licensed under a Creative Commons Attribution 4.0 International License, which permits use, sharing, adaptation, distribution and reproduction in any medium or format, as long as you give appropriate credit to the original author(s) and the source, provide a link to the Creative Commons licence, and indicate if changes were made. The images or other third party material in this article are included in the article's Creative Commons licence, unless indicated otherwise in a credit line to the material. If material is not included in the article's Creative Commons licence and your intended use is not permitted by statutory regulation or exceeds the permitted use, you will need to obtain permission directly from the copyright holder. To view a copy of this licence, visit http://creativeco mmons.org/licenses/by/4.0/. The Creative Commons Public Domain Dedication waiver (http://creativecommons.org/publicdomain/ zero/1.0/) applies to the data made available in this article, unless otherwise stated in a credit line to the data. 
temperatures [4-6]. Treatment options depend on the types of AIHA, with corticosteroids or supportive care as the mainstay of the treatment [7].

MAHA is a descriptive term for non-immune hemolysis resulting from intravascular $\mathrm{RBC}$ fragmentation [8]. Its main difference from AIHA is that patients with MAHA get negative in DAT [8]. The prominent causes of MAHA are thrombotic thrombocytopenic purpura (TTP) and hemolytic uremic syndrome (HUS) [8]. The disease can be hereditary or acquired by inhibiting autoantibodies [9]. TTP is mainly caused by a severely reduced activity of the von Willebrand factor-cleaving protease, ADAMTS13. Its standard treatment is plasma exchange (PEX) in conjunction with corticosteroids [10]. Typical infection-associated HUS is triggered by Shiga toxin producing Escherichia coli, and primary HUS is caused by complement dysregulation. The standard treatment is eculizumab for HUS [11].

Rituximab (RTX) is a B cell depleting monoclonal antibody which binds to cluster of differentiation (CD) 20 expressed on the surface of $B$ cell that produces anti-RBC antibodies. It has been used as a therapeutic biologic agent in B cell lymphoma and leukemia [12]. A systematic review has discussed about safety and efficacy of RTX in immune-mediated disorders [13]. A meta-analysis has shown high short-term benefit/risk ratio of RTX in AIHA [14]. A randomized controlled trial (RCT) has revealed that RTX combined with prednisone may confer a better benefit/risk ratio than prednisone alone for treating adults with newly-diagnosed warm-type AIHA (wAIHA) [15]. A phase 2 study showed a high remission and survival rate for TTP patients treated with PEX and RTX [16]. Overall, RTX may be effective in AIHA or, presumably in MAHA. However, the evidence of favorability for this treatment modality is not yet clear. To further investigate the efficacy and safety of RTX in AIHA and MAHA, we conducted this systematic review and meta-analysis.

\section{Methods}

\section{Data sources and search strategy}

All stages of the present investigation followed the Meta-analysis Of Observational Studies in Epidemiology (MOOSE) and Preferred Reporting Items for Systematic reviews and Meta-Analyses (PRISMA) guidelines [17, 18]. An exhaustive literature search was carried out on PubMed, Cochrane Library, Embase, and Google Scholar from the inception to Oct 15, 2018. The search criteria included AIHA, MAHA, thrombotic microangiopathy (TMA), TTP or HUS and RTX in Medical Subject Heading $(\mathrm{MeSH})$, limiting to human studies.

\section{Study selection}

We included clinical trials or observational studies published in English, which assessed the efficacy and safety of RTX in AIHA or MAHA (TTP/HUS). Duplicated investigations, studies in other research scopes or without desired outcomes, enrollment with insufficient sample size of less than 10 patients, and those without full article publication were excluded.

\section{Data extraction}

The extracted data included sample size, population, age, gender, dosage and framework of RTX treatment, the first author's name, year of publication, study design, time of first evaluation, mean follow-up time and definition of treatment efficacy. The number of patients with overall response (OR) and/or complete response $(\mathrm{CR})$ was extracted from each study. When available, the eventual relapse, side effects or toxicities were also collected.

\section{Quality assessment}

Quality was assessed using the revised and validated version of Methodological Index for NOn-Randomized Studies (MINORS) [19]. Non-comparative studies were scored on clearly stated aim, inclusion of consecutive patients, prospective collection of data, appropriate endpoints, unbiased assessment of the study endpoint, appropriate follow-up time period, loss to follow-up of less than 5\%, and prospective calculation of the study size. Additional criteria for comparative studies were an adequate control group, contemporary control groups, baseline equivalence of groups, and adequate statistical analyses. Studies received 0 to 2 points for each of these components. The total score ranged from 0 to 24 points for comparative studies and 0 to 16 points for non-comparative studies. Scores no less than 18 in comparative studies and no less than 12 in non-comparative studies were considered to be with high quality and were included in quantitative analysis.

\section{Data synthesis and analysis}

Efficacy was assessed by overall response rate (ORR) and complete response rate (CRR). Weighted mean proportions of response rate were calculated over all studies that included in the quantitative analysis, and relative ORR and relative CRR were calculated over comparative studies. As for the safety, adverse events (AEs) were extracted from all included studies. The weighted mean relapse rate (RR) in all studies and relative $R R$ in comparative studies were calculated. We used a random-effects model to control the between-study variance and to produce an overall 
summary as described by Dersimonian and Laird [20]. $\mathrm{R}$ Software (package metafor, version 2.0-0) was used for all analyses.

We assessed statistical heterogeneity by using $\mathrm{I}^{2}$ statistic and Cochran's $Q$ test. An $I^{2}$ statistic with values greater than $50 \%$ or $\mathrm{Q}$ test with $p$-value less than 0.1 indicates substantial heterogeneity. To explain heterogeneity, the effects of covariates on response rate were investigated using mixed-effects meta-regression. The risk of publication bias was determined by the method of funnel plot and Egger's regression test, which plots the natural $\log$ of effect sizes versus their standard error, and linear regression of funnel plot test asymmetry.

\section{Results}

\section{Study selection}

Figure 1 summarized the flow chart of the systematic literature review with meta-analysis. A total of 2732 articles were initially identified through electronic searching. After duplication of the same publications in different databases were removed, the titles and abstracts of the remaining studies were reviewed, and 60 articles with potentially relevant studies were further identified in full-text. Finally, 43 published studies were determined to be eligible and were included in the qualitative analysis. Among 43 studies included in the qualitative analysis, 37 studies reached the cut point of high quality and were included in the quantitative analysis [15, 16, 21-55].

\section{Description of the studies}

Characteristics of the included studies are shown in Table 1. Among 37 studies included in the quantitative analysis, 24 studies dealt with AIHA, while 13 included MAHA patients. Most of them were observational studies, and 10 of them were comparative studies, encompassing 7 AIHA studies and 3 MAHA studies. Sample size varied from 10 to 86 patients, the mean age was 50.6 years old, and the mean proportion of male was $41.0 \%$. Patients mostly received four weekly infusions of RTX at $375 \mathrm{mg} / \mathrm{m}^{2}$. Time of the first evaluation was 0.2 month to 1 year, and the follow-up time ranged from 6 to 83 months.

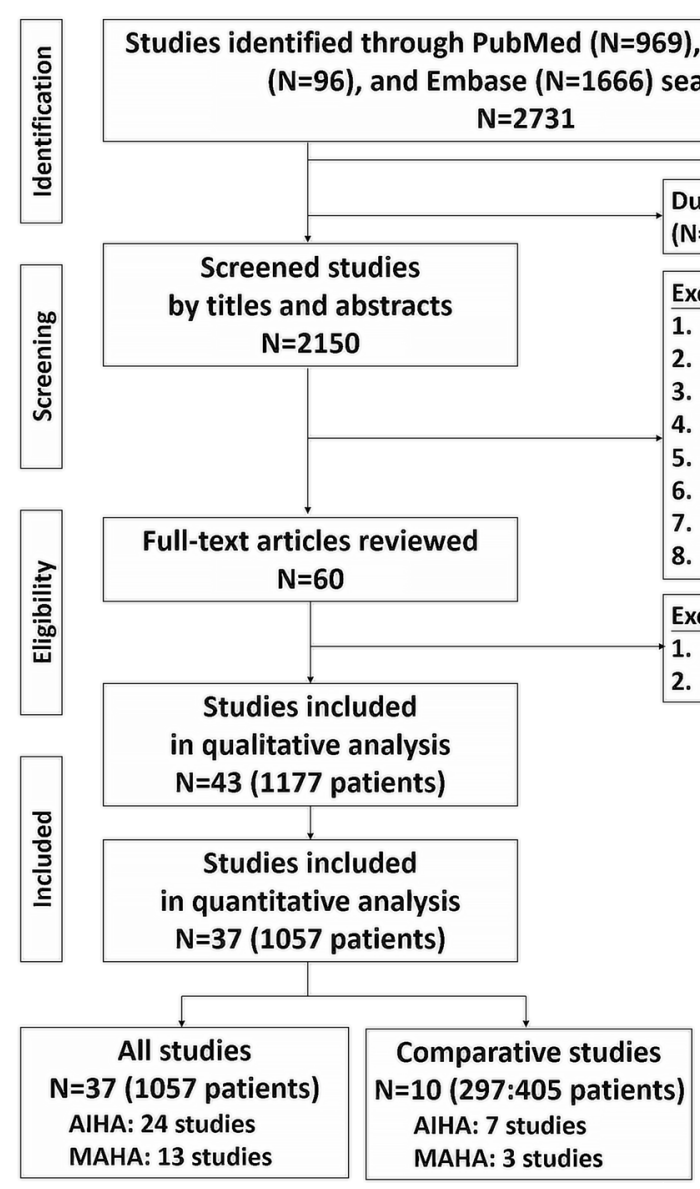

Fig. 1 Flow chart of the systematic literature review with meta-analysis 
Table 1 Characteristics of studies included in quantitative analysis

\begin{tabular}{lll}
\hline Disease & AlHA & MAHA \\
\hline All studies & 24 studies & 13 studies \\
37 studies & 746 patients & 311 patients \\
1057 patients & & \\
& WAlHA & TTP \\
& 8 studies & 12 studies \\
& 182 patients & 297 patients \\
& CAD & HUS \\
& 5 studies & 1 study \\
& 173 patients & 14 patients \\
Comparative studies & 7 studies & 3 studies \\
10 studies & $232: 303$ patients & $65: 102$ patients \\
297:405 patients & & \\
\hline
\end{tabular}

Publication year: 2004-2018; sample size: 10-86 (mean age: 50.6, mean male proportion: $41.0 \%$ ); rituximab regimen: 28 with $375 \mathrm{mg} / \mathrm{m}^{2} 4$ weekly, 8 with other regimen (e.g. $100 \mathrm{mg} 4$ weekly); study design: 13 clinical trials, 24 observational studies; 1 st evaluation time: 0.2 months- 1 year; follow-up time: $6-83$ months

\section{Efficacy in all studies}

After pooling the effect of 37 studies, we got the weighted mean proportion of response rate. The ORR was $84 \%$ (95\% CI $0.80-0.88)$ with high heterogeneity $\left(\mathrm{I}^{2}=75.76 \%\right.$, $p<0.01$ ), as shown in Fig. 2a. Funnel plot of ORR was asymmetrical as shown in Fig. 3a, which indicated possible publication bias (Egger's regression test, $p<0.0001$ ). The CRR was $61 \%(95 \%$ CI $0.49-0.73)$ with significant heterogeneity $\left(\mathrm{I}^{2}=97.46 \%, p<0.01\right)$, as shown in Fig. $2 \mathrm{~b}$. Funnel plot of CRR was symmetrical, indicating no publication bias (Fig. 3b, Egger's regression test, $p=0.631$ ).

Subgroup analyses were done because of the high heterogeneity, which were shown in Table 2 in detail. For AIHA, ORR was 79\% (95\% CI 0.73-0.84) and CRR was 44\% (95\% CI 0.33-0.55). Eight studies provided data for wAIHA with ORR of 79\% (95\% CI 0.69-0.90) and CRR was $49 \%$ (95\% CI $0.22-0.77$ ). For cold agglutinin disease (CAD), ORR was 66\% (95\% CI 0.57-0.76) and CRR was 14\% (95\% CI 0.03-0.25). As for MAHA, the response rate was 93\% (95\% CI 0.89-0.97). Further dividing MAHA into TTP and HUS, the response rate was $92 \%$ (95\% CI $0.88-0.96)$ in TTP and 97\% (95\% CI 0.88-1.06) in HUS respectively. There was no significant difference wherever these data came from with regards to the study design or dosage regimen. All treatment modalities in MAHA studies were in combination with PEX or plasma infusion. Therefore, we couldn't analyze the impact of different treatment modalities in MAHA studies. But the response rate of RTX alone were similar to combination therapy in AIHA (RTX alone: $82 \%$ in OR, $44 \%$ in CR; treatments in combination: $74 \%$ in OR, $45 \%$ in CR).

We further carried out meta-regression to find out another factors that may influence the response rate
(Table 3). Among all the factors we tested, ORR and CRR were only significantly associated with age (ORR: $r^{2}=23.29, p=0.0103$; CRR: $\left.r^{2}=45.37, p<0.0001\right)$ as shown in Fig. 4a, b, respectively.

Among 872 patients included, there were 163 relapse events, with an overall RR of $21 \%$ (95\% CI 0.15-0.26) (Fig. 2c). Because funnel plot for RR was asymmetrical (Fig. 3c), it is possible that there is a publication bias (Egger's regression test, $p<0.0001$ ). In a further subgroup analysis (Table 2), RR was $28 \%$ (95\% CI $0.20-0.36$ ) in AIHA and 9\% (95\% CI 0.05-0.13) in MAHA respectively. However, meta-regression failed to demonstrate any other additional confounding factor (Table 3).

\section{Safety in all studies}

Briefly, 32 studies reported 138 AEs in 851 patients. The overall AE rate was $13 \%$ (95\% CI $0.10-0.17$ ). Among them, 33 events $(23.9 \%)$ were infusion-related reactions, such as fever, chills, skin rash, and allergic reactions, 34 events (24.6\%) were infections, and 40 events (29.0\%) were hematologic abnormalities, mostly neutropenia. Besides, there were 3 mortalities (0.3\%), including one early death from uncontrolled hemolysis [38]. The 2nd fatal patient died because of delayed treatment [55]. The 3rd fatal patient died shortly after RTX therapy, which was also claimed to be partially contributing to the death [42]. Importantly, there is a critical issue about hepatitis $B$ virus reactivation ( $\mathrm{HBVr}$ ) regarding AE of RTX. There was no records about it in the present meta-analysis. The previous epidemiological study provided prevalence estimates for a mean global $\mathrm{HBsAg}$ prevalence of $4.9 \%$ [56]. In Taiwan, the mean HBsAg prevalence goes to $13.7 \%$ [56]. So, rationale for the absence of $\mathrm{HBVr}$ as AE in the present investigation may be that the included studies were all from Western countries. It is conceivable that quite different conclusion might be reached if the studies are conducted using Taiwanese data, which will be interesting.

\section{Efficacy in comparative studies}

After pooling the effect of 10 comparative studies, we got the relative response rate. As shown in Fig. 2d, relative OR was 1.18 (95\% CI 1.02-1.36) with high heterogeneity $\left(\mathrm{I}^{2}=72.10 \%, p<0.01\right)$. Funnel plot for relative $\mathrm{OR}$ was asymmetrical as shown in Fig. 3d, indicating possible publication bias (Egger's regression test, $p=0.0056$ ). On the other hand, relative CR was 1.17 (95\% CI 0.98-1.39) with heterogeneity $\left(\mathrm{I}^{2}=51.98 \%, p=0.03\right.$, Fig. 2e) and with a symmetrical funnel plot indicating the absence of publication bias (Egger's regression test, $p=0.1736$, Fig. 3e).

Sensitivity analysis was carried out via leave-one-out approach in both relative ORR and relative CRR. In the 


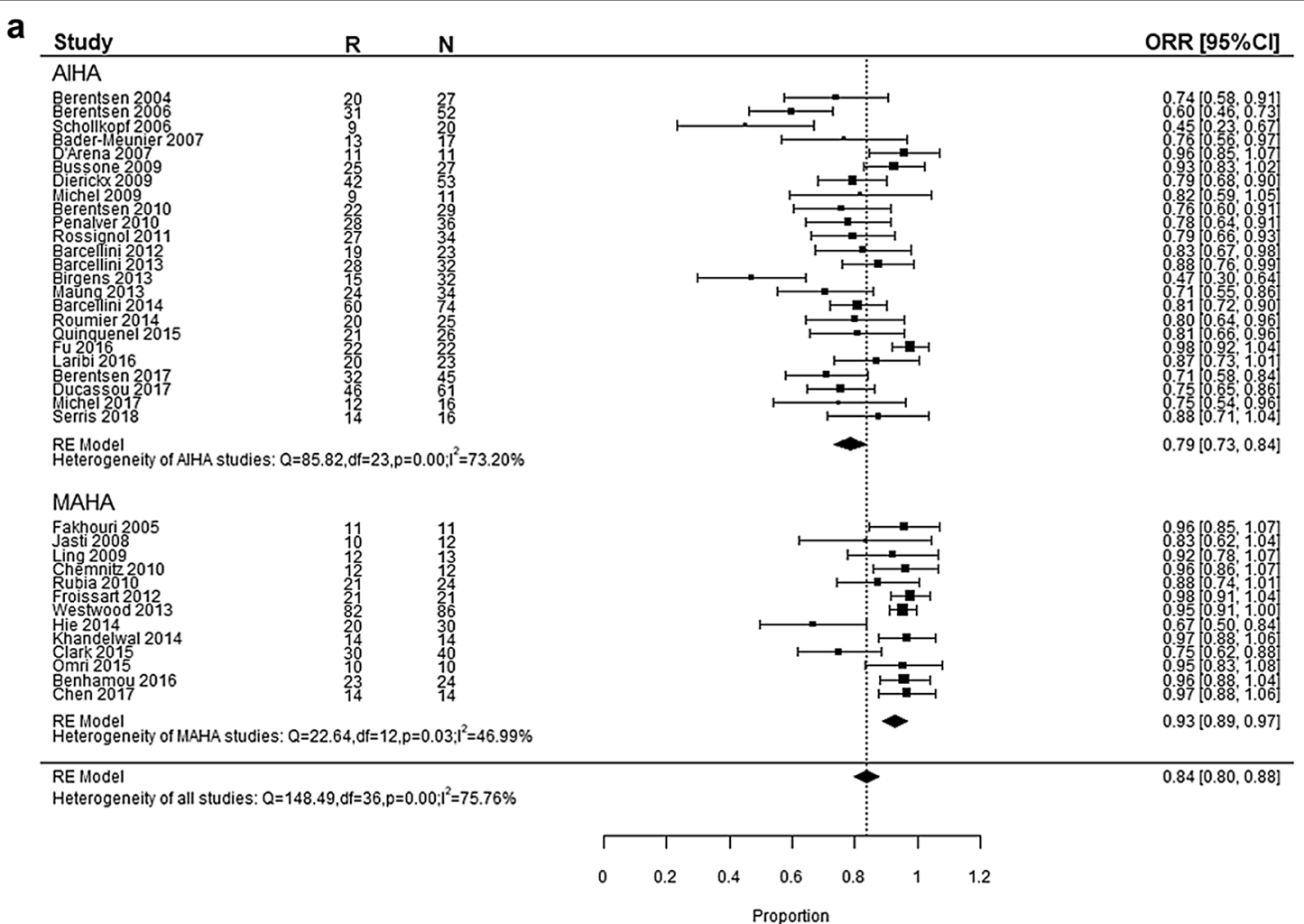

b

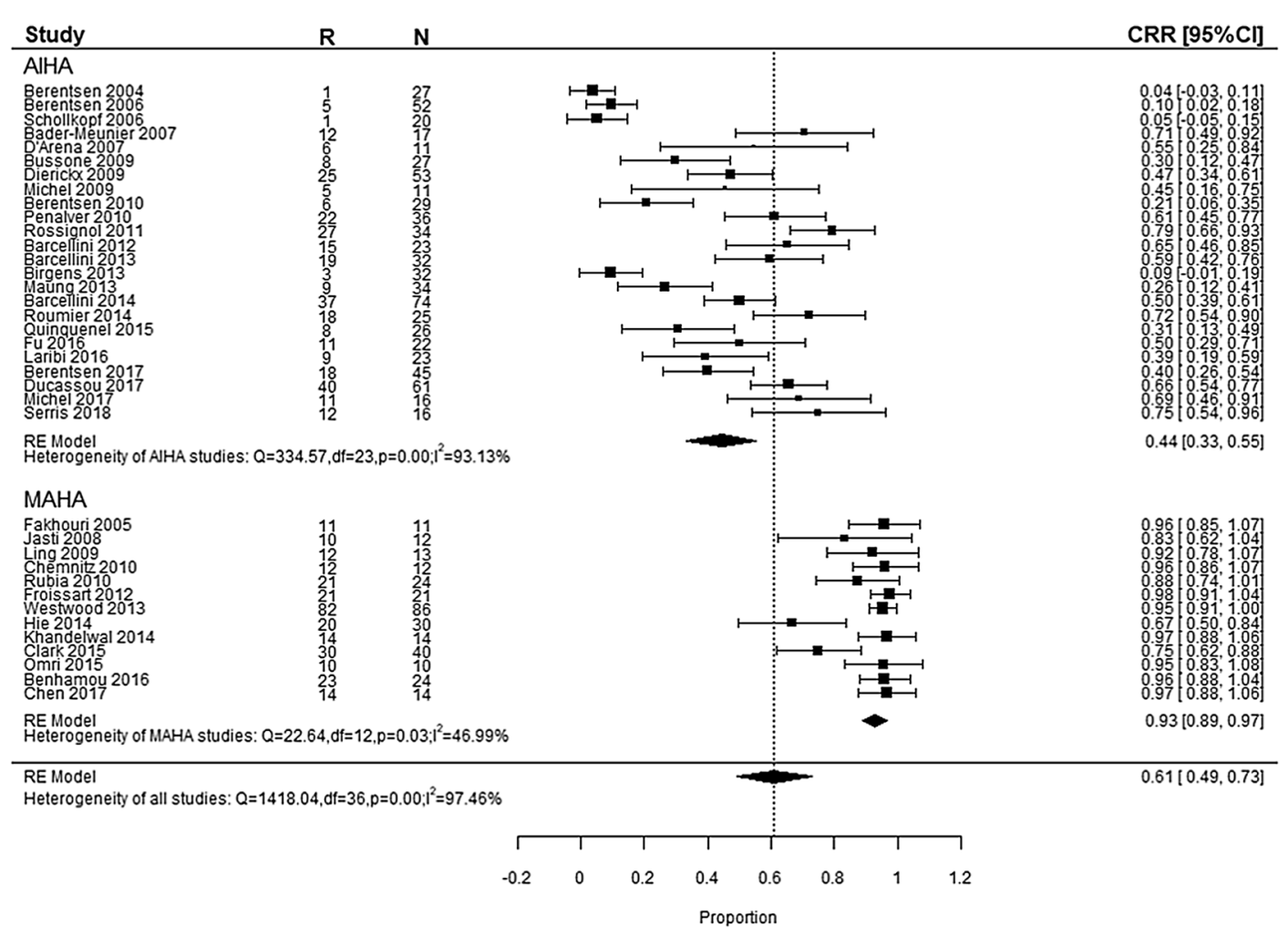

Fig. 2 Forest plot. a Overall response rate of rituximab in AlHA and MAHA. b Complete response rate of rituximab in AlHA and MAHA. c Relapse rate of rituximab in AlHA and MAHA. d Relative overall response rate of rituximab in AlHA and MAHA. e Relative complete response rate of rituximab in AlHA and MAHA. $\mathbf{f}$ Relative relapse rate of rituximab in AlHA and MAHA 


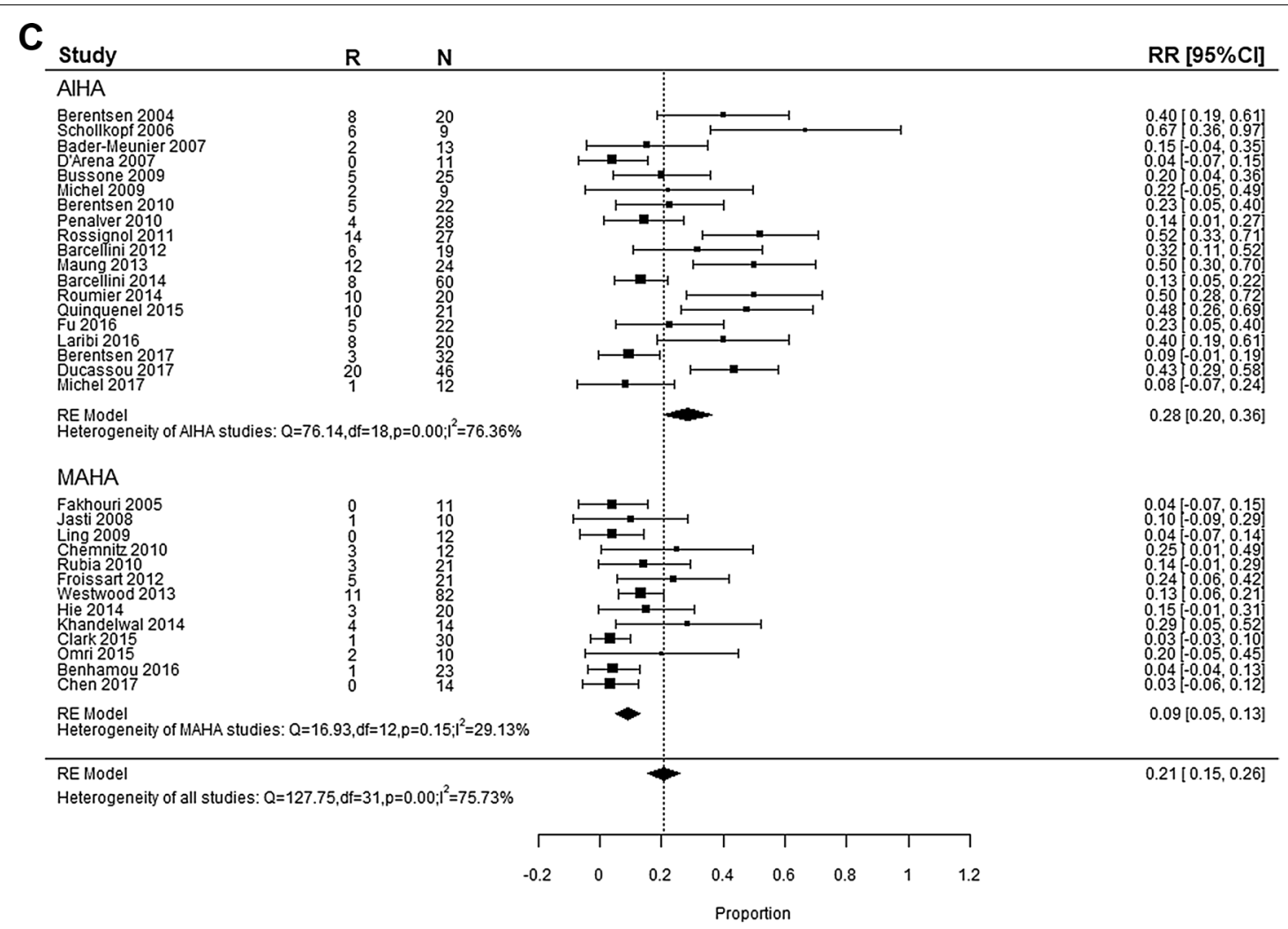

D

Study

$\underset{R}{\text { Rituximab }} \underset{\mathbf{R}}{\text { Comparator }}$

Relative ORR [95\% Cl]

AlHA

Berentsen 2006

Michel 2009

Birgens 2013

Barcellini 2014

Roumier 2014

Fu 2016

Michel 2017

$\begin{array}{cc} & \\ 31 & 52 \\ 9 & 11 \\ 15 & 32 \\ 60 & 74 \\ 20 & 25 \\ 22 & 22 \\ 12 & 16\end{array}$

RE Model

$\begin{array}{cc}9 & 72 \\ 15 & 19 \\ 16 & 32 \\ 83 & 108 \\ 19 & 29 \\ 25 & 27 \\ 5 & 16\end{array}$

Heterogeneity of AlHA studies: $Q=24.59, d f=6, p=0.00 ; l^{2}=75.60 \%$

MAHA

Froissart 2012

Hie 2014

Khandelwal 2014

$21 \quad 21$

$\begin{array}{ll}20 & 30 \\ 14 & 14\end{array}$

4153

RE Model

Heterogeneity of MAHA studies: $Q=7.10, d f=2, p=0.03 ;\left.\right|^{2}=71.83 \%$

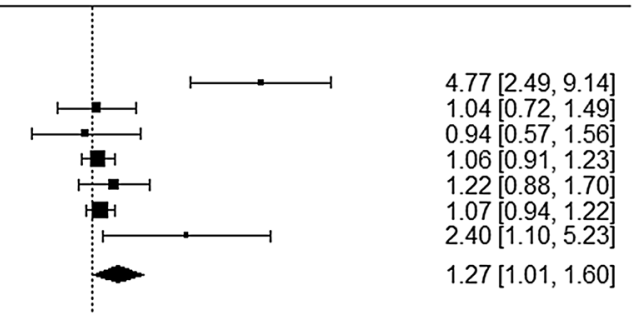

RE Model

Heterogeneity of all studies: $Q=32.25, d f=9, p=0.00 ; I^{2}=72.10 \%$

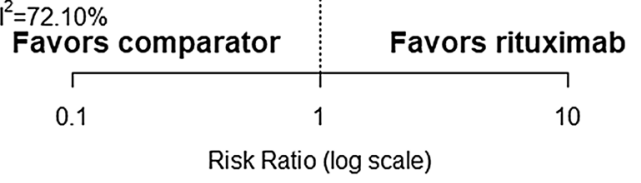

Fig. 2 continued 


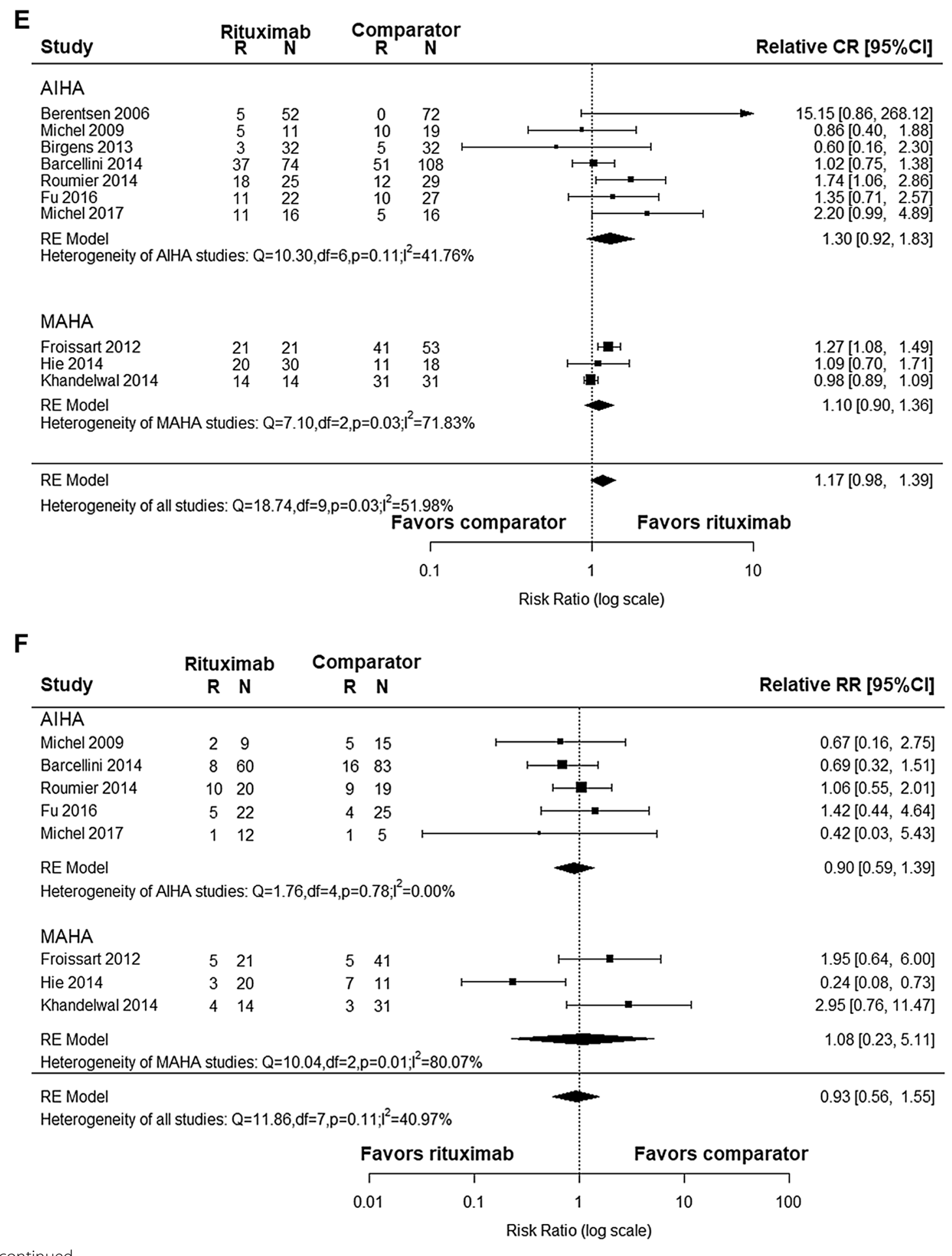

Fig. 2 continued 
$\mathbf{a}$

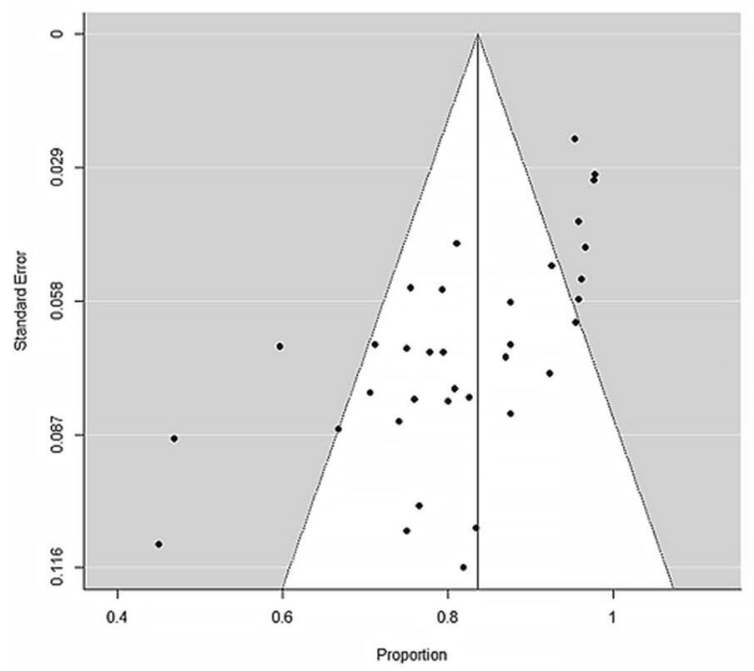

c

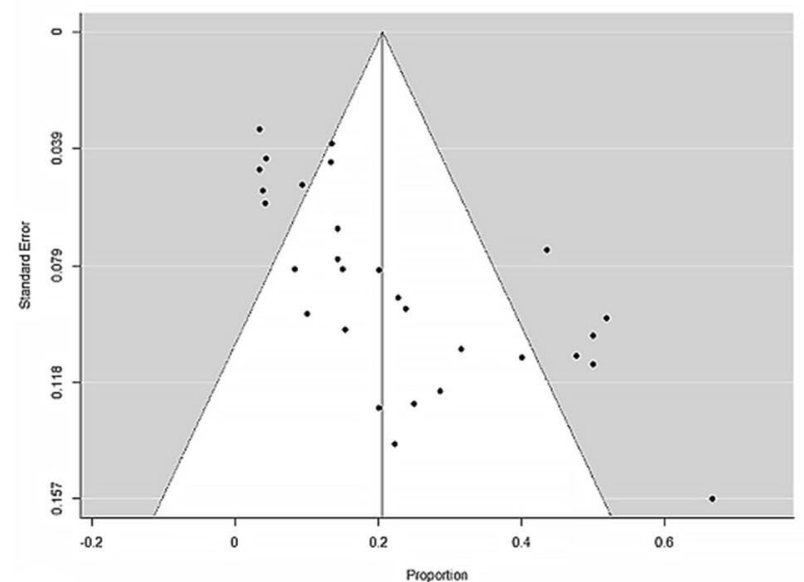

$\mathbf{e}$

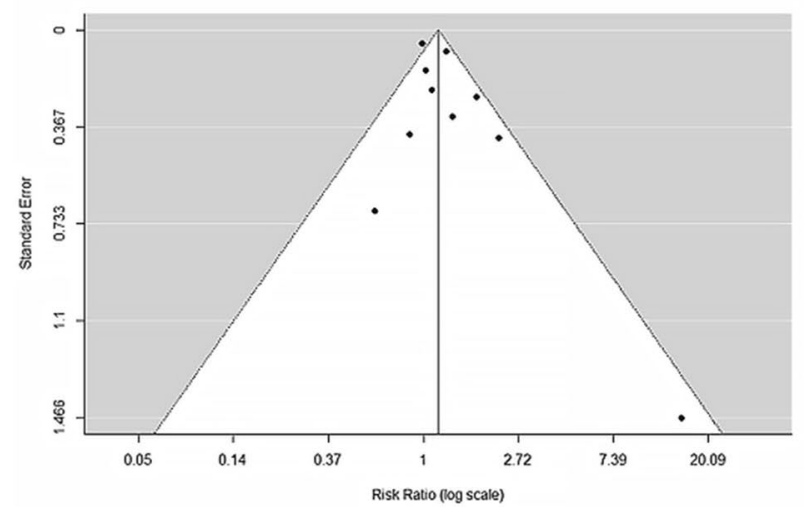

b

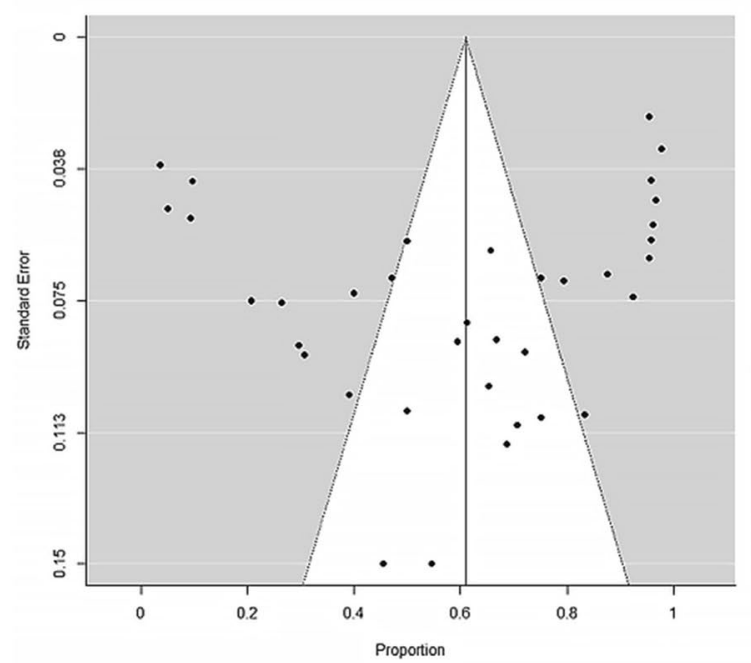

d
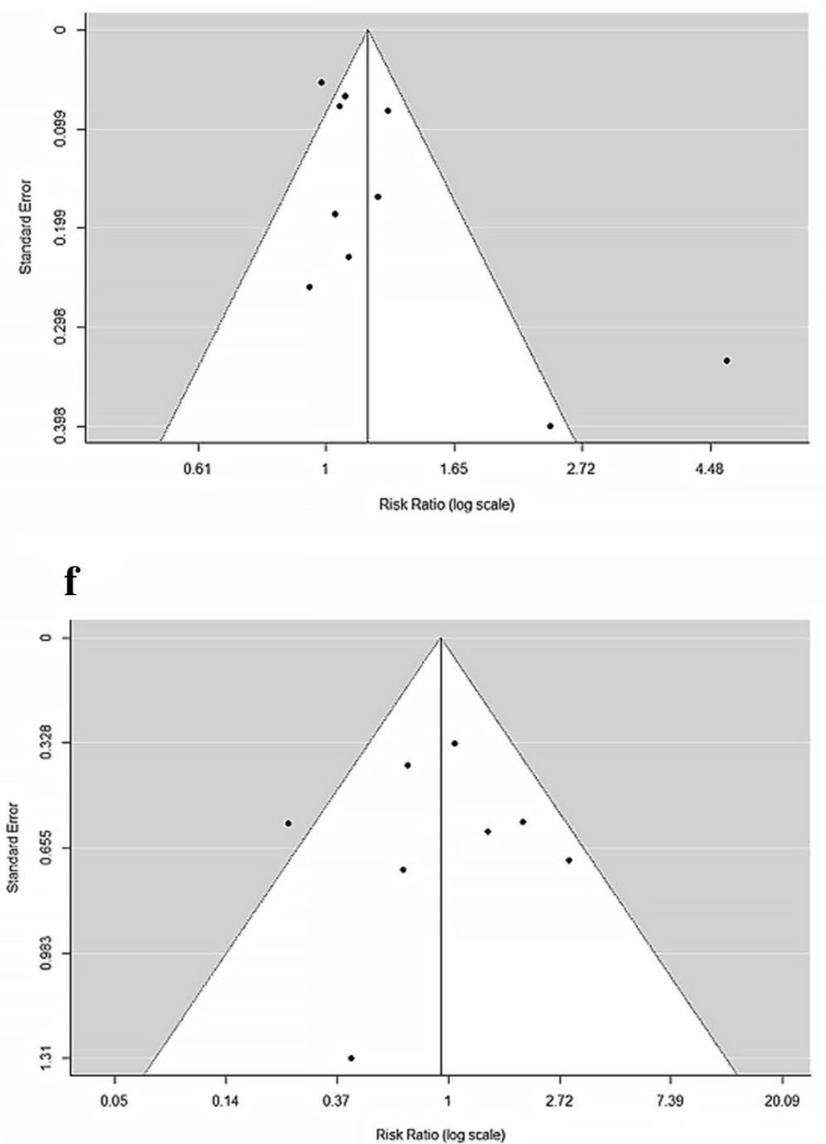

Fig. 3 Funnel plot. a. Publication bias of overall response rate of rituximab in AlHA and MAHA. $\mathbf{b}$ Publication bias of complete response rate of rituximab in AlHA and MAHA. c Relapse rate of rituximab in AlHA and MAHA. d Publication bias of relative overall response rate of rituximab in AlHA and MAHA. e Publication bias of relative complete response rate of rituximab in AlHA and MAHA. $\mathbf{f}$ Publication bias of relative relapse rate of rituximab in AlHA and MAHA 
Table 2 Subgroup analysis

\begin{tabular}{|c|c|c|c|c|c|c|c|c|c|}
\hline \multirow[t]{2}{*}{ Subgroup category } & \multicolumn{3}{|l|}{ OR rate } & \multicolumn{3}{|l|}{ CR rate } & \multicolumn{3}{|l|}{ RR } \\
\hline & Study, n & ORR $(95 \% \mathrm{Cl})$ & $I^{2}(\%)$ & Study, $n$ & CRR (95\% Cl) & $I^{2}(\%)$ & Study, $\mathrm{n}$ & RR $(95 \% \mathrm{Cl})$ & $I^{2}(\%)$ \\
\hline Overall & 37 & $0.84(0.80,0.88)$ & 75.76 & 37 & $0.61(0.49,0.73)$ & 97.46 & 32 & $0.21(0.15,0.26)$ & 75.73 \\
\hline \multicolumn{10}{|l|}{ Study design } \\
\hline Clinical trial & 13 & $0.80(0.72,0.89)$ & 83.81 & 13 & $0.56(0.32,0.80)$ & 98.54 & 11 & $0.15(0.07,0.22)$ & 73.10 \\
\hline Observational study & 24 & $0.85(0.80,0.89)$ & 69.89 & 24 & $0.64(0.51,0.76)$ & 95.79 & 21 & $0.23(0.17,0.30)$ & 72.29 \\
\hline \multicolumn{10}{|l|}{ Diagnosis } \\
\hline AlHA & 24 & $0.79(0.73,0.84)$ & 73.20 & 24 & $0.44(0.33,0.55)$ & 93.13 & 19 & $0.28(0.20,0.36)$ & 76.36 \\
\hline WAlHA & 8 & $0.79(0.69,0.90)$ & 75.89 & 8 & $0.49(0.22,0.77)$ & 96.27 & 7 & $0.31(0.14,0.47)$ & 82.22 \\
\hline CAD & 5 & $0.66(0.57,0.76)$ & 45.99 & 5 & $0.14(0.03,0.25)$ & 82.57 & 4 & $0.31(0.10,0.53)$ & 81.81 \\
\hline MAHA & 13 & $0.93(0.89,0.97)$ & 46.99 & 13 & $0.93(0.89,0.97)$ & 46.99 & 13 & $0.09(0.05,0.13)$ & 29.13 \\
\hline TTP & 12 & $0.92(0.88,0.96)$ & 50.74 & 12 & $0.92(0.88,0.96)$ & 50.74 & 12 & $0.08(0.04,0.12)$ & 21.38 \\
\hline HUS & 1 & $0.97(0.88,1.06)$ & & 1 & $0.97(0.88,1.06)$ & & 1 & $0.29(0.05,0.52)$ & \\
\hline \multicolumn{10}{|l|}{ Dosage regimen } \\
\hline $375 \mathrm{mg} / \mathrm{m}^{2} 4$ weekly & 28 & $0.83(0.78,0.88)$ & 78.64 & 28 & $0.62(0.48,0.77)$ & 98.03 & 24 & $0.20(0.14,0.26)$ & 77.50 \\
\hline Other regimen & 8 & $0.84(0.76,0.91)$ & 67.49 & 8 & $0.56(0.45,0.67)$ & 70.80 & 7 & $0.24(0.13,0.32)$ & 72.87 \\
\hline \multicolumn{10}{|c|}{ Treatment modalities of AlHA } \\
\hline RTX alone & 14 & $0.82(0.76,0.88)$ & 72.74 & 14 & $0.44(0.29,0.59)$ & 93.22 & 12 & $0.30(0.20,0.40)$ & 78.27 \\
\hline In combination & 10 & $0.74(0.66,0.81)$ & 59.22 & 10 & $0.45(0.27,0.63)$ & 93.70 & 7 & $0.26(0.12,0.39)$ & 76.19 \\
\hline
\end{tabular}

Table 3 Meta-regression

\begin{tabular}{|c|c|c|c|c|c|c|c|c|c|}
\hline & \multicolumn{3}{|l|}{ OR rate } & \multicolumn{3}{|l|}{ CR rate } & \multicolumn{3}{|l|}{ RR } \\
\hline & Study (n) & $\mathrm{R}^{2}(\%)$ & $p$-value & Study (n) & $\mathrm{R}^{2}(\%)$ & $P$-value & Study (n) & $R^{2}(\%)$ & $p$-value \\
\hline Sample size & 37 & 5.11 & 0.1079 & 37 & 1.29 & 0.2262 & 32 & 0.00 & 0.7044 \\
\hline Year of publication & 37 & 0.00 & 0.3522 & 37 & 5.83 & 0.0905 & 32 & 0.00 & 0.9247 \\
\hline Age & 30 & 23.29 & 0.0103 & 30 & 45.37 & $<0.0001$ & 27 & 0.00 & 0.3689 \\
\hline Proportion of male & 30 & 0.00 & 0.6095 & 30 & 0.00 & 0.5294 & 27 & 0.00 & 0.4814 \\
\hline Evaluation time & 29 & 3.70 & 0.2370 & 29 & 0.00 & 0.4967 & 27 & 0.00 & 0.6003 \\
\hline Follow-up time & 37 & 8.59 & 0.1167 & 37 & 0.00 & 0.9396 & 32 & 0.00 & 0.6639 \\
\hline Quality score & 37 & 0.00 & 0.1886 & 37 & 0.10 & 0.3369 & 32 & 0.42 & 0.3695 \\
\hline
\end{tabular}

former, leaving "Berentsen et al. 2006" out resulted in the reduction in the overall heterogeneity significantly, coming to an ORR of 1.09 (95\% CI 1.00-1.19). On the other hand, leaving "Khandelwal et al. 2014" out led to a reduction in overall CRR heterogeneity significantly, coming to 1.24 (95\% CI 1.03-1.49).

Among 10 comparative studies, 8 studies reported RR. The overall relative RR was 0.93 (95\% CI 0.561.55, Fig. 2f) with a symmetrical funnel plot (Egger's regression test, $p=0.8543$, Fig. $3 f$ ), indicating that there were no publication bias. Regarding the sensitivity analysis (Table 4), leaving "Hie et al. 2014" out resulted in reduction in the overall heterogeneity significantly, coming to 1.09 (95\% CI $0.74,1.60)$.

\section{Safety in comparative studies}

Among 10 comparative studies, 6 studies documented AEs in both groups. In RTX group, there were 34 AEs in 130 patients, and there were 55 AEs in 188 patients in comparative group. The relative $\mathrm{AE}$ rate was 0.74 (95\% CI 0.33-1.63) for RTX.

\section{Discussion}

The results in the present "efficacy in AIHA study" were consistent with those reported previously [14]. However, our "efficacy in wAIHA" was higher than those reported in cold agglutinin disease (CAD). This implies that warm type AIHAs are more likely to be resulted from B cell hyperactivity. Moreover, the present study on "the efficacy 


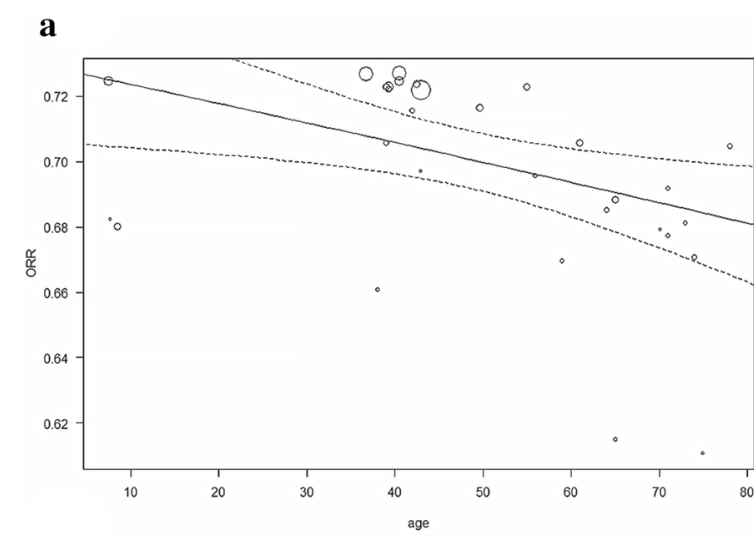

b

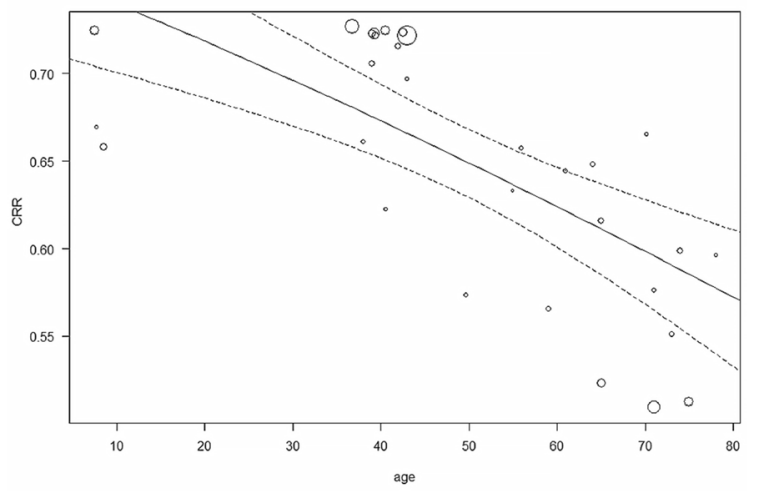

Fig. 4 Bubble plot. a Relation of age and overall response rate. $\mathbf{b}$ Relation of age and complete response rat

of RTX in MAHA" is the first one to our knowledge. We have found that the response rate of RTX was higher in MAHA. Furthermore, these effects were the same in patients either with TTP or HUS. The reason for this is unclear because apparently MAHA is not developing on the basis of deranged B cell regulation. However, HUS or TTP has been reported to be originated from autoantibodies such as ant-dsDNA, anticardiolipin antibodies, \&/ or other autoantibodies against ADAMS13 [57, 58].

In subgroup analysis, regimens with different dosage of RTX showed a similar response rate. Most studies used the regimen of $375 \mathrm{mg} / \mathrm{m}^{2}$ 4-weekly, which might contribute to the effects. These results are interesting because monoclonal antibody drugs are quite different from traditional small molecule drugs in that they are acting on the cells via the receptors or ligands. Since the cells usually have their own threshold or affinity limitation, the traditional dose-response relationship cannot be applied to this scenario. Moreover, the initial effect of the biologics on the cell can even be amplified or reduced via cell-cell contact or crosstalk. Further investigations may be necessary to determine the optimal dosage for RTX in AIHA and MAHA. When it comes to different treatment modalities, response rate of RTX alone were similar to combination therapy in AIHA, i.e., RTX alone can be reasonably considered in patients with AIHA. Furthermore, regarding the effect of age on the response rate of RTX in HA patients, we found that the response rate was significantly reduced along with aging of the recipients. It may imply that senility is aligned with degeneration of the immunity such that the immune therapy on B cells is also turning to be ineffective. However, it is also possible that younger patients present with a more benign form of the disease. As for RR, our result in AIHA (28\%) were consistent with those from previous meta-analysis (27\%) [14]. Patients with MAHA exhibited lower RR (9\%) in the present study. Although there were some patients with relapse in this group, most of them recovered after repeating with RTX.

RTX seems safe and well-tolerated in AIHA and MAHA. This was consistent with previous meta-analysis [14]. Few AEs have been reported (13\%) in all of our included studies and even when they were present, the majority of them were otherwise mild. However, there are some common AEs in the in-label use of RTX, which were more than $25 \%$ in incidence, such as infusion reactions. Overall, RTX showed lower AE rate in AIHA and MAHA than in other diseases.

On the other hand, there is a critical issue about hepatitis $B$ virus reactivation $(\mathrm{HBVr})$ regarding $\mathrm{AE}$ of RTX. Indeed, there was no records for this in the present meta-analysis. In the epidemiological studies, the average global prevalence of HBV infection is $4.8 \%$ whereas the figure is as high as $23.7 \%$ in Taiwan, which is among the highest in the Asia-Pacific region [55]. The absence of $\mathrm{HBV}$ related $\mathrm{AE}$ in the present meta-analysis is conceivable because the included studies were all carried out in Western countries. If the studies done in Asia-Pacific region including Taiwan were included, the results are expected to be quite different, necessitating further relevant investigations.

The present investigation has provided overwhelming evidence for the first time that RTX is effective for AIHA and MAHA, compared to the conventional treatment modalities that did not include RTX. A previous metaanalysis only estimated the pooled mean response rate of RTX in AIHA] [14]. In sensitivity analysis of ORR, getting rid of Berentsen's data in 2006 could reduce the overall heterogeneity significantly [22]. This is because they used a quite different comparators to assess the effect of RTX. Similarly, in sensitivity analysis of CRR, getting rid of Khandelwal's data in 2014 resulted in a significant reduction of the overall heterogeneity [52]. The cause of it may be that their data only included HUS. Nevertheless, the response rate still favored RTX in both MAHA and AIHA. 


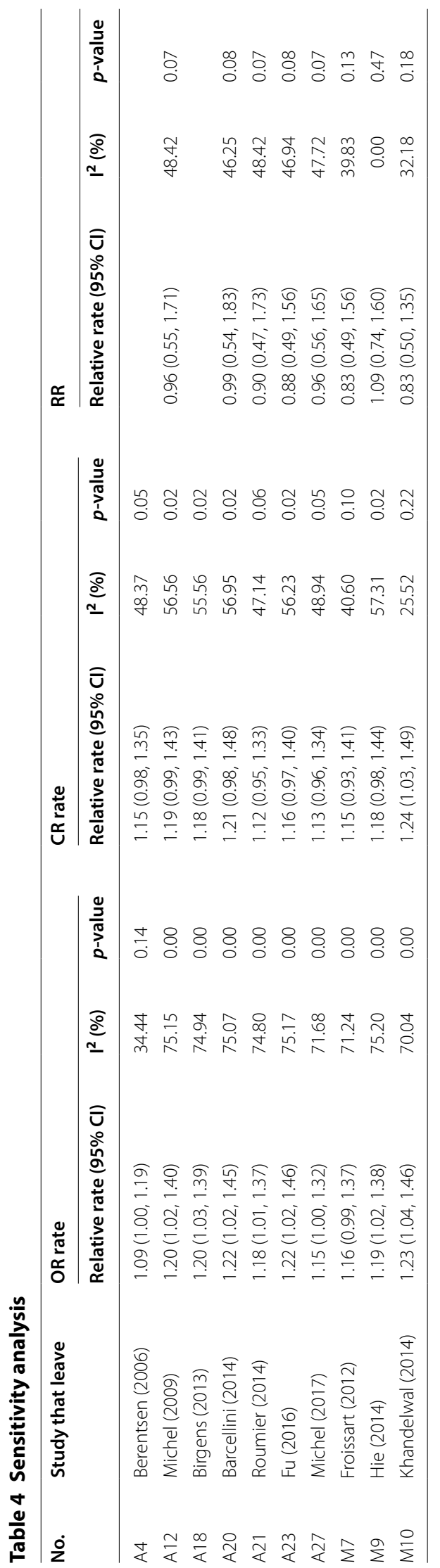


As for the RR, there were no differences between treatments with and without RTX. In sensitivity analysis, getting rid of Hie's data in 2014 resulted in reduction in the overall heterogeneity significantly. Their investigation was the only study significantly favoring rituximab with low RR. The follow-up time of their data was the longest (5 years), which has indicated that the long-term effect of RTX is better than that of standard cares. However, the RRs were still not different between two groups after leaving "Hie et al. 2014" out.

In the analysis of comparative studies, the $\mathrm{AE}$ rates were not different between treatments with and without RTX. Taken together, the safety of RTX seemed similar to that of the conventional treatment modalities.

In spite of the significant findings demonstrated in the present meta-analysis, there were still several limitations in it. Firstly, although we have searched extensively in the 4 databases for all the relevant studies, we could only found 2 randomized controlled trials. Although this has been inevitable because AIHA and MAHA are rare diseases in real life, it may cause a lower level of evidence. Secondly, our overall results showed high heterogeneity. To figure out the reasons for this, we carried out meta-regression and found that age might have been the factor that influences the response rate. The various comparators in comparative studies may have also contributed. Lastly, although our analytic process followed the MOOSE and PRISMA guidelines, publication bias existed in the estimation of ORR and RR. There are several reasons to result in the publication bias. For example, inclusion criteria in a meta-analysis may be biased if the selection is restricted to published trials or to trials published in English language journals [59]. On the other hand, most research with published bias lack studies with poor results, since studies with poor results are most likely not to be published. It may cause overestimation of the pooled effects. However, the studies that are lacking in our research are studies with better results, i.e., the lack of those studies in our research may only cause further underestimation of the effect. Hence, our results should have been convincing.

\section{Conclusion}

RTX shows a high overall effect (84\%) in AIHA and MAHA, and an even higher effect (93\%) in MAHA subgroup. It also shows a better effect in both AIHA and MAHA in comparison with other treatment modalities. Moreover, the RR of the diseases after RTX treatment might have been low. Finally, RTX is safe and well-tolerated for the treatment of HA. Few AEs have been reported with most of them being mild, and the $\mathrm{AE}$ rate was similar to those reported in other treatment modalities.

\section{Abbreviations}

ADAMTS13: A disintegrin and metalloproteinase with a thrombospondin type 1 motif, member 13; AE: Adverse event; AlHA: Autoimmune hemolytic anemia; CAD: Cold agglutinin disease; CD: Cluster of differentiation; CRR: Complete response rate; DAT: Direct antiglobulin test; HA: Hemolytic anemia; HUS: Hemolytic-uremic syndrome; MAHA: Microangiopathic hemolytic anemia; MeSH: Medical Subject Headings; MINORS: Methodological Index for NOn-Randomized Studies; MOOSE: Meta-analysis Of Observational Studies in Epidemiology; ORR: Overall response rate; PRISMA: Preferred Reporting Items for Systematic reviews and Meta-Analyses; RBC: Red blood cell; RR: Relapse rate; RTX: Rituximab; TMA: Thrombotic microangiopathy; TTP: Thrombotic thrombocytopenic purpura; vWF: von Willebrand factor; WAlHA: Warm-reactive autoimmune hemolytic anemia.

\section{Acknowledgements}

This work was partly supported by the grants from Taipei Veterans General Hospital (V107D37-002-MY3-1) and Ministry of Sciences \& Technology, Executive Yuan, Taiwan (MOST107-2314-B-075-051-MY3).

\section{Disclaimer}

The views expressed are those of the author(s) and not necessarily those of the MOST or Taipei VGH.

\section{Authors' contributions}

SHC, YCC, and YLC performed the systematic literature review under the supervision of CYT. SHC and YCC carried out the study. All authors participated in the discussion for the interpretation of results. YLC organized and chaired the meetings, along with YCC and JCY. SHC wrote the draft manuscript. CYT and HTL gave critical reviews and revision of the manuscript. All contents of the article has been approved by all coauthors. All authors read and approved the final manuscript.

\section{Funding \\ None.}

\section{Availability of data and materials}

All data generated or analyzed during this study are included in the manuscript.

\section{Ethics approval and consent to participate}

This is not applicable for this review.

\section{Consent for publication}

We declared that the manuscript is original, has not been published before, and is not currently being considered for publication elsewhere.

\section{Competing interests}

We declared that we have no competing interests.

\section{Author details}

${ }^{1}$ Institute of Pharmacology, National Yang-Ming University, Taipei, Taiwan. ${ }^{2}$ Department of Pharmacy, Taipei Veterans General Hospital, Taipei, Taiwan. ${ }^{3}$ Division of Allergy Immunology \& Rheumatology, Taipei Veterans General Hospital, 201 Shih-Pai Rd Sec 2, Taipei 112, Taiwan. . Division of Nephrology, Taipei Veterans General Hospital, Taipei, Taiwan. ${ }^{5}$ Division of Rheumatology Immunology \& Allergy, Department of Internal Medicine, National Taiwan University Hospital, Taipei, Taiwan.

Received: 9 February 2020 Accepted: 28 March 2020

Published online: 15 April 2020

\section{References}

1. Dhaliwal G, Cornett PA, Tierney LM Jr. Hemolytic anemia. Am Fam Physician. 2004;69:2599-606.

2. Barcellini W, Fattizzo B. Clinical applications of hemolytic markers in the differential diagnosis and management of hemolytic anemia. Dis Mark. 2015;2015:635670.

3. Barcellini W. Immune hemolysis: diagnosis and treatment recommendations. Semin Hematol. 2015;52:304-12. 
4. Bass GF, Tuscano ET, Tuscano JM. Diagnosis and classification of autoimmune hemolytic anemia. Autoimmun Rev. 2014;13:560-4.

5. Michel M. Classification and therapeutic approaches in autoimmune hemolytic anemia: an update. Expert Rev Hematol. 2011;4:607-18.

6. Berentsen S, Sundic T. Red blood cell destruction in autoimmune hemolytic anemia: role of complement and potential new targets for therapy. Biomed Res Int. 2015;2015:363278.

7. Hill QA, Stamps R, Massey E, et al. The diagnosis and management of primary autoimmune haemolytic anaemia. Br J Haematol. 2017;176:395-411.

8. Shenkman B, Einav Y. Thrombotic thrombocytopenic purpura and other thrombotic microangiopathic hemolytic anemias: diagnosis and classification. Autoimmun Rev. 2014;13:584-6.

9. Tsai HM, Lian EC. Antibodies to von Willebrand factor-cleaving protease in acute thrombotic thrombocytopenic purpura. NEJM. 1998;339:1585-94.

10. Scully M, Hunt BJ, Benjamin S, et al. Guidelines on the diagnosis and management of thrombotic thrombocytopenic purpura and other thrombotic microangiopathies. Br J Haematol. 2012;158:323-35.

11. Taylor CM, Machin S, Wigmore SJ, et al. Clinical practice guidelines for the management of atypical haemolytic uraemic syndrome in the United Kingdom. Br J Haematol. 2010;148:37-47.

12. Liu D, Zhao J. Frontline therapies for untreated chronic lymphoid leukemia. Exp Hematol Oncol 2019;8:15. https://doi.org/10.1186/s4016 4-019-0139-8

13. Kaegi C, Wuest B, Schreiner J, et al. Systematic review of safety and efficacy of rituximab in treating immune-mediated disorders. Front Immunol. 2019:10:1990.

14. Reynaud $\mathrm{Q}$, Durieu I, Dutertre $\mathrm{M}$, et al. Efficacy and safety of rituximab in auto-immune hemolytic anemia: a meta-analysis of 21 studies. Autoimmun Rev. 2015;14:304-13

15. Michel M, Terriou L, Roudot-Thoraval F, et al. A randomized and doubleblind controlled trial evaluating the safety and efficacy of rituximab for warm auto-immune hemolytic anemia in adults (the RAIHA study). Am J Hematol. 2017;92:23-7.

16. Clark WF, Rock G, Barth D, et al. A phase-Il sequential case-series study of all patients presenting to four plasma exchange centres with presumed relapsed/refractory thrombotic thrombocytopenic purpura treated with rituximab. Br J Haematol. 2015;170:208-17.

17. Stroup DF, Berlin JA, Morton SC, et al. Meta-analysis of observational studies in epidemiology: a proposal for reporting. Meta-analysis Of Observational Studies in Epidemiology (MOOSE) group. JAMA. 2000;283:2008-12.

18. Moher D, Liberati A, Tetzlaff J, et al. Preferred reporting items for systematic reviews and meta-analyses: The PRISMA statement. J Clin Epidemiol. 2009:62:1006-12.

19. Slim K, Nini E, Forestier D, et al. Methodological index for non-randomized studies (minors): development and validation of a new instrument. ANZ J Surg. 2003;73:712-6.

20. DerSimonian R, Laird N. Meta-analysis in clinical trials. Control Clin Trials. 1986;7:177-88

21. Berentsen $S$, Ulvestad E, Gjertsen BT, et al. Rituximab for primary chronic cold agglutinin disease: a prospective study of 37 courses of therapy in 27 patients. Blood. 2004;103:2925-8.

22. Berentsen S, Ulvestad E, Langholm R, et al. Primary chronic cold agglutinin disease: a population based clinical study of 86 patients. Haematologia. 2006;91:460-6.

23. Schöllkopf C, Kjeldsen L, Bjerrum OW, et al. Rituximab in chronic cold agglutinin disease: a prospective study of 20 patients. Leuk Lymphoma. 2006:47:253-60.

24. Bader-Meunier B, Aladjidi N, Bellmann F, et al. Rituximab therapy for childhood Evans syndrome. Haematologia. 2007;92:1691-4.

25. D'Arena G, Califano C, Annunziata M, et al. Rituximab for warm-type idiopathic autoimmune hemolytic anemia: a retrospective study of 11 adult patients. Eur J Haematol. 2007;79:53-8.

26. Bussone G, Ribeiro E, Dechartres A, et al. Efficacy and safety of rituximab in adults' warm antibody autoimmune haemolytic anemia: retrospective analysis of 27 cases. Am J Hematol. 2009:84:153-7.

27. Dierickx $D$, Verhoef $G$, van Hoof $A$, et al. Rituximab in auto-immune haemolytic anaemia and immune thrombocytopenic purpura: a Belgian retrospective multicentric study. J Inter Med. 2009;266:484-91.
28. Michel M, Chanet V, Dechartres A, et al. The spectrum of Evans syndrome in adults: new insight into the disease based on the analysis of 68 cases. Blood. 2009:114:3167-72.

29. Berentsen S, Randen U, Vågan AM, et al. High response rate and durable remissions following fludarabine and rituximab combination therapy for chronic cold agglutinin disease. Blood. 2010;1 16:3180-4.

30. Peñalver FJ, Alvarez-Larrán A, Díez-Martin JL, et al. Rituximab is an effective and safe therapeutic alternative in adults with refractory and severe autoimmune hemolytic anemia. Ann Hematol. 2010;89:1073-80.

31. Rossignol J, Michallet AS, Oberic L, et al. Rituximab-cyclophosphamidedexamethasone combination in the management of autoimmune cytopenias associated with chronic lymphocytic leukemia. Leukemia. 2011:25:473-8

32. Barcellini W, Zaja F, Zaninoni A, et al. Low-dose rituximab in adult patients with idiopathic autoimmune hemolytic anemia: clinical efficacy and biologic studies. Blood. 2012;119:3691-7.

33. Barcellini W, Zaja F, Zaninoni A, et al. Sustained response to low-dose rituximab in idiopathic autoimmune hemolytic anemia. Eur J Haematol. 2013;91:546-51.

34. Birgens $\mathrm{H}$, Frederiksen $\mathrm{H}$, Hasselbalch $\mathrm{HC}$, et al. A phase III randomized trial comparing glucocorticoid monotherapy versus glucocorticoid and rituximab in patients with autoimmune haemolytic anaemia. Br J Haematol. 2013;163:393-9.

35. Maung SW, Leahy M, O'Leary HM, et al. A multi-centre retrospective study of rituximab use in the treatment of relapsed or resistant warm autoimmune haemolytic anaemia. Br J Haematol. 2013;163:118-22.

36. Barcellini W, Fattizzo B, Zaninoni A, et al. Clinical heterogeneity and predictors of outcome in primary autoimmune hemolytic anemia: a GIMEMA study of 308 Patients. Blood. 2014;124:2930-6.

37. Roumier M, Loustau V, Guillaud C, et al. Characteristics and outcome of warm autoimmune hemolytic anemia in adults: new insights based on a single-center experience with 60 patients. Am J Hematol. 2014;89:E150-5.

38. Quinquenel A, Willekens C, Dupuis J, et al. Bendamustine and rituximab combination in the management of chronic lymphocytic leukemiaassociated autoimmune hemolytic anemia: a multicentric retrospective study of the French CLL intergroup (GCFLLC/MW and GOELAMS). Am J Hematol. 2015:90:204-7.

39. Fu $R$, Yan $S$, Wang $X$, et al. A monocentric retrospective study comparing pulse cyclophosphamide therapy versus low dose rituximab in the treatment of refractory autoimmune hemolytic anemia in adults. Int J Hematol. 2016:104:462-7.

40. Laribi K, Bolle D, Ghnaya H, et al. Rituximab is an effective and safe treatment of relapse in elderly patients with resistant warm AlHA. Ann Hematol. 2016;95:765-9.

41. Berentsen $\mathrm{S}$, Randen U, Oksman M, et al. Bendamustine plus rituximab for chronic cold agglutinin disease: results of a Nordic prospective multicenter trial. Blood. 2017;130:537-41.

42. Ducassou S, Leverger $\mathrm{G}$, Fernandes $\mathrm{H}$, et al. Benefits of rituximab as a second-line treatment for autoimmune haemolytic anaemia in children: a prospective French cohort study. Br J Haematol. 2017;177:751-8.

43. Serris A, Amoura Z, Canouï-Poitrine F, et al. Efficacy and safety of rituximab for systemic lupus erythematosus-associated immune cytopenias: a multicenter retrospective cohort study of 71 adults. Am J Hematol. 2018:93:424-9.

44. Fakhouri F, Vernant JP, Veyradier A, et al. Efficiency of curative and prophylactic treatment with rituximab in ADAMTS13-deficient thrombotic thrombocytopenic purpura: a study of 11 cases. Blood. 2005;106:1932-7.

45. Jasti S, Coyle T, Gentile T, et al. Rituximab as an adjunct to plasma exchange in TTP: a report of 12 cases and review of literature. J Clin Apheresis. 2008;23:151-6

46. Ling HT, Field JJ, Blinder MA. Sustained response with rituximab in patients with thrombotic thrombocytopenic purpura: a report of 13 cases and review of the literature. Am J Hematol. 2009:84:418-21.

47. Chemnitz JM, Uener J, Hallek M, et al. Long-term follow-up of idiopathic thrombotic thrombocytopenic purpura treated with rituximab. Ann Hematol. 2010;89:1029-33.

48. Rubia JDL, Moscardó F, Gómez MJ, et al. Efficacy and safety of rituximab in adult patients with idiopathic relapsing or refractory thrombotic 
thrombocytopenic purpura: results of a Spanish multicenter study. Transf Apheresis Sci. 2010;43:299-303.

49. Froissart A, Buffet M, Veyradier A, et al. Efficacy and safety of first-line rituximab in severe, acquired thrombotic thrombocytopenic purpura with a suboptimal response to plasma exchange: experience of the French Thrombotic Microangiopathies Reference Center. Crit Care Med. 2012:40:104-11.

50. Westwood JP, Webster H, McGuckin S, et al. Rituximab for thrombotic thrombocytopenic purpura: benefit of early administration during acute episodes and use of prophylaxis to prevent relapse. J Thromb Haemost. 2013;11:481-90.

51. Hie M, Gay J, Galicier L, et al. Preemptive rituximab infusions after remission efficiently prevent relapses in acquired thrombotic thrombocytopenic purpura. Blood. 2014;124:204-10.

52. Khandelwal P, Gupta A, Sinha A, et al. Effect of plasma exchange and immunosuppressive medications on antibody titers and outcome in anticomplement factor $\mathrm{H}$ antibody-associated hemolytic uremic syndrome. Pediat Nephrol. 2014;30:451-7.

53. El Omri H, Taha RY, Gamil A, et al. Efficacy and safety of rituximab for refractory and relapsing thrombotic thrombocytopenic purpura: a cohort of 10 cases. Clin Med Insights Blood Disord. 2015;8:1-7.
54. Benhamou Y, Paintaud G, Azoulay E, et al. Efficacy of a rituximab regimen based on B cell depletion in thrombotic thrombocytopenic purpura with suboptimal response to standard treatment: results of a phase II, multicenter noncomparative study. Am J Hematol. 2016;91:1246-51.

55. Chen H, Fu A, Wang J, et al. Rituximab as first-line treatment for acquired thrombotic thrombocytopenic purpura. J Int Med Res. 2017;45:1253-60.

56. Razavi-Shearer D, Gamkrelidze I, Nguyen MH, et al. Global prevalence, treatment, and prevention of hepatitis B virus infection in 2016: a modelling study. Lancet Gastroenterol Hepatol. 2018;3:383-403.

57. Raufi AG, Scott S, Darwish O, Harley K, Kahlon K, Desai S, Lu Y, Tran M-H. Atypical hemolytic uremic syndrome secondary to lupus nephritis, responsive to eculizumab. Hematol Rep. 2016;8:6625.

58. Dolin HH, Dziuba M, Pappada SM, Papadimos TJ. Presumed antiphospholipid syndrome and thrombotic thrombocytopenic purpura: an infrequent association. Clin Case Rep. 2019;7:1984-8.

59. Biljana $\mathrm{M}$, Jelena $\mathrm{M}$, Branislav J, et al. Bias in meta-analysis and funnel plot asymmetry. Stud Health Technol Inform. 1999;68:323-8.

\section{Publisher's Note}

Springer Nature remains neutral with regard to jurisdictional claims in published maps and institutional affiliations.
Ready to submit your research? Choose BMC and benefit from:

- fast, convenient online submission

- thorough peer review by experienced researchers in your field

- rapid publication on acceptance

- support for research data, including large and complex data types

- gold Open Access which fosters wider collaboration and increased citations

- maximum visibility for your research: over $100 \mathrm{M}$ website views per year

At BMC, research is always in progress.

Learn more biomedcentral.com/submissions 